\title{
An improved technique for power transformer protection using fuzzy logic protective relaying
}

\author{
Marwa M. Marei, Manal H. Nawir, Ali Abdul Razzaq Altahir \\ Electrical and Electronic Engineering Department, Faculty of Engineering, University of Kerbala, Iraq
}

\begin{tabular}{l} 
Article Info \\
\hline Article history: \\
Received Feb 21, 2021 \\
Revised Apr 30, 2021 \\
Accepted May 1, 2021 \\
\hline
\end{tabular}

\section{Keywords:}

Digital protection Fuzzy logic controller Internal faults

Karbala transmission

Protective relaying

Transformer protection

\begin{abstract}
The three-phase power transformer in the transmission or distribution substations represents one of the essential devices on electric power networks. Losing this devise cause a disconnection of the power utility to a large number of electrical loads. The robust protection system must be designed to protect the device during abnormal operations. A complete protection system for a poly-phase power transformer for one of the Karbala transmission networks (East Karbala substation) is modeled and simulated, adopting a fuzzy logic protective relaying using MATLAB/SIMULINK environment. This study discusses fuzzy logic-based relaying for a power transformer safety, as well as internal faults that are clearly identified. Two principles of operation are used to protect the transformer; differential relay and overcurrent relay. The differential relay is proposed as the unit protection, while the overcurrent is backup protection. The proposed fuzzy logic controller (FLC) is used to detect abnormal operation; it is also modeled to organize the operation between unit and backup protection. The numerical results clarify that the proposed model can perform fast, rigorous, and authoritative protection for the transformer. Also, modeling of the protection mode decreases the complexity of designing various subsystem and combining them in one controller.
\end{abstract}

This is an open access article under the CC BY-SA license.

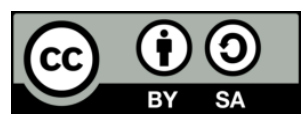

\section{Corresponding Author:}

Marwa Mohammad Marei

Department of Electrical and Electronic Engineering

University of Kerbala

Kerbala, Iraq

Email: marwa.alkhuzaei@uokerbala.edu.iq

\section{INTRODUCTION}

Power system protection is an electrical power network that deals with the electrical power systems by disconnecting the faulty part from the power system's healthy part. Protection systems are used to sense and disconnect any fault at the power system automatically. According to its importance, an electric power transformer must be protected from internal and external faults depending on many relays, depending on different fault detection strategies. In this work, a power transformer protected using a proposed protection system; this proposed system consists of a digital differential relay designed to work as the unit protection while an overcurrent as a secondary (backup) protection to protect the device during unit protection system failure and fuzzy logic controller (FLC) used to control and coordinate the operation of these relays [1].

Since the magnetizing inrush current has a significant second harmonic portion, a harmonic-restrained differential relay is formed. This scenario can be improved because harmonics occur in the power system's normal state, and the quantity of second frequency components in the inrush state can be reduced by changing the core steel [2]. In the presence of differential currents, this scenario cannot 
distinguish between fault and inrush. For versatility in the face of changing power system conditions, a new relaying technique with high reliability is needed. For protective relaying, several new artificial intelligence features have been created. Miriyala et al. [3] suggested differential protective relay based on fuzzy logic, and the wavelet-based algorithm is reported.

In this study, one FLC used to do two functions: first, it is used to detect the fault adopting two principals of operation (differential relay and overcurrent relay), and second is coordinate the operation of the unit and backup protection systems. The proposed system decreases the complexity of designing various subsystems and combining them in one controller. The rest of this study is prepared as follows: the materials and methods related to research are described in section 2, such as differential relay and overcurrent relay. In section 3, the construction of a fuzzy protective relay has been presented. The proposed model, including fuzzification and defuzzification with specific rules, has been clarified in section 4 . In section 5 , the case study simulation and findings have been prepared and discussed. Finally, in section 6, conclusions are drawn.

\section{MATERIALS AND METHODS}

\subsection{Differential relay}

The concept of differential comparison can understand by referring to Figure 1 [4]-[6]. During regular operation, the primary current Ip entering the transformer's primary terminal is amounting to the current, leaving it from the secondary terminal at every instant [7], [8]. The secondary current in the pilot line of the current transformer (CT) A, which is existing at the first terminal of protected transformer, is [9], [10]:

$$
I_{A S}=\alpha_{A} I_{p}-I_{A e}
$$

For the current transformer B, which is located at the second terminal of the protected power transformer, the equation becomes as follows:

$$
I_{B S}=\alpha_{B} I_{p}-I_{B e}
$$

If the transformation ratios are equal, i.e., $\alpha_{A}=\alpha_{B}=a$, the relay operating current $I_{o p}$ is stated by:

$$
I_{o p}=I_{A e}-I_{B e}
$$

Through regular process of the system and exterior faults duration, the relay operating current $I_{o p}$ is tiny, but never be nil [11]-[13] where;

$a_{A}$ : The transformation ratio of the CTA

$I_{A e}:$ CT excitation current on the secondary measured in A

$a_{B}$ : Transformer B transformation ratio

$I_{B e}$ : CT B excitation current on the secondary measured in A

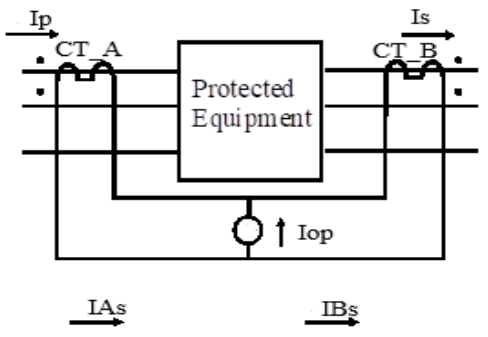

Figure 1. Differential relay principle of operation

\subsection{Overcurrent relay}

The power system's development is essential to provide electric energy with high quality to consumers and keep up with demand increasing [14], [15]. Over-current protection has evolved from 90 years ago. It is the simplest, earliest, and cheapest sample of protection and remains publicly used today in the power industry [16], [17]. The threshold current is exceeded, the relay sends out a trip signal with a predetermined delay time [18], [19]. These relays are categorized according to their time characteristics, such 
as definite time, instantaneous, very steep time, inverse time, very inverse time, and extremely inverse time. The following is a summary of the time-current relay characteristic:

$$
T=\frac{K T M S}{I^{n}-1}
$$

$T: \quad$ The relay time of operation

$K$ : The constant design parameter

$T M S$ : The time multiplier setting

$N$ : $\quad$ Algebraic function index characteristic

I : $\quad$ The current of relay multiplied by tap setting

\section{FUZZY LOGIC PROTECTIVE RELAY}

The fuzzy logic technique is a type of logic system; it is a critical technique and importance due to a fuzzy method for the system dialectic under confusion and illustrates in unfaithful way near that for human thought. This technique quite varies from Boolean logic and classic logic method; these ways suppose the exact variables in true or false, while fuzzy logic technique is a functional method for recognition and prepare an accurate adjustment that understands a valuation or approximate answer for a problem depending on the store of approximate information, not complete or unreliable [20], [21].

When it is complicated to encode a mathematical representation, the fuzzy logic technique is very efficient and is the best solution [22]. A fuzzy logic system consists of input variables and output variables associated with specific rules depending on the function designed for it. Fuzzy logic technique is used for power contingency analysis and control [23]-[25]. The major component of fuzzy inference systems is shown in Figure 2.

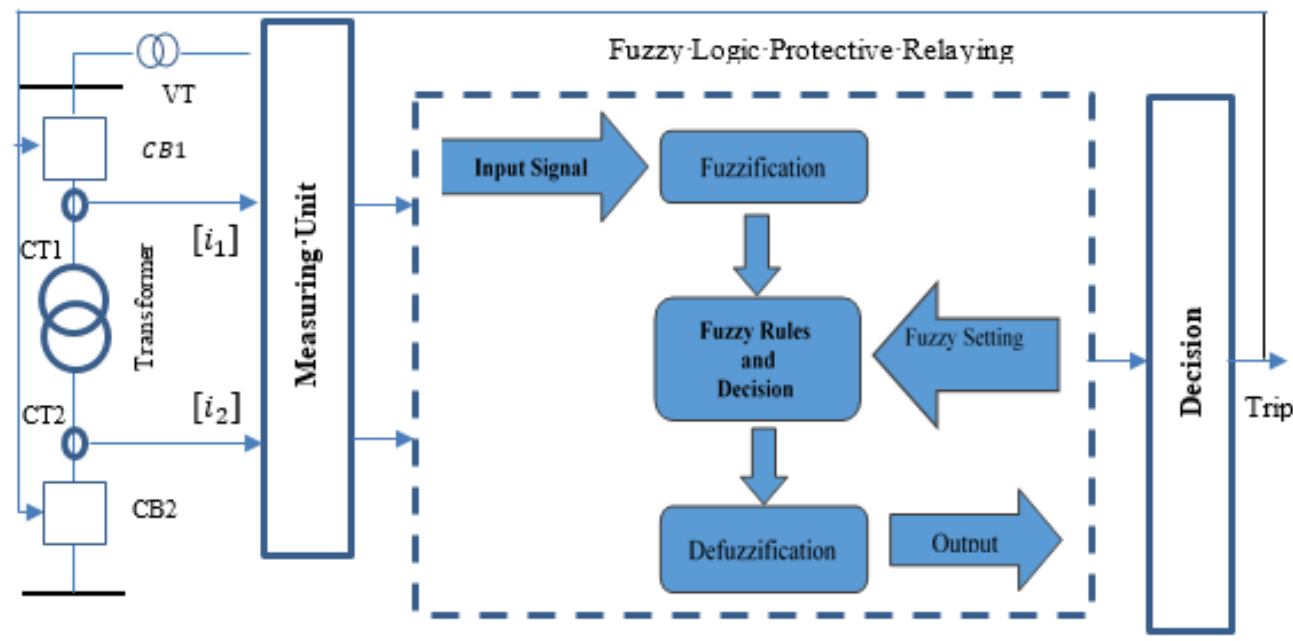

Figure 2. The basic construction of fuzzy logic protective relaying

For the differential relay, after the current passing through the current transformers (CT1 and CT2), the difference is compared with a reference value representing the normal operation difference with an acceptable increase according to the normal variation of loads. The value of the normal and abnormal difference is represented as a membership function on the input1 of FLC. The current value of the normal and abnormal activity is expressed as a membership function on the FLC's input2 for the overcurrent relay. Then logical rules are used to detect and coordinate the operation of the two relays as listed in the second paragraph.

\section{THE PROPOSED MODEL}

In this work, a complete protection system depending on FLC has been presented. This model can detect and make an isolation decision using one controller. Since the protected devise is a transformer, the proposed protection system contains a differential relay for the unit protection relay and an overcurrent relay for the backup (secondary) protection. The construction of the suggested fuzzy logic protective relaying is shown in Figure 3. 


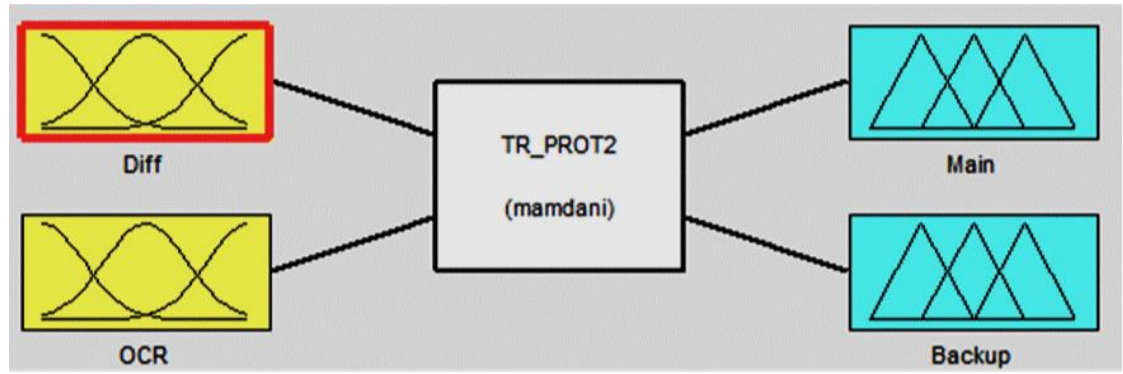

Figure 3. Fuzzy logic protective structure of the proposed model

\subsection{Proposed technique membership functions}

The proposed controller contains two input variables and two output variables as listed below: Input1 (Diff): represents the detection signal that comes from the differential relay. Input2 (OCR): represents the detection signal that comes from the overcurrent relay. Output1 (Main): represents an isolation signal to the unit protection system.

Output2 (Backup): represents an isolation signal to the backup protection system. Figure 4 show the input variables membership function (MF).

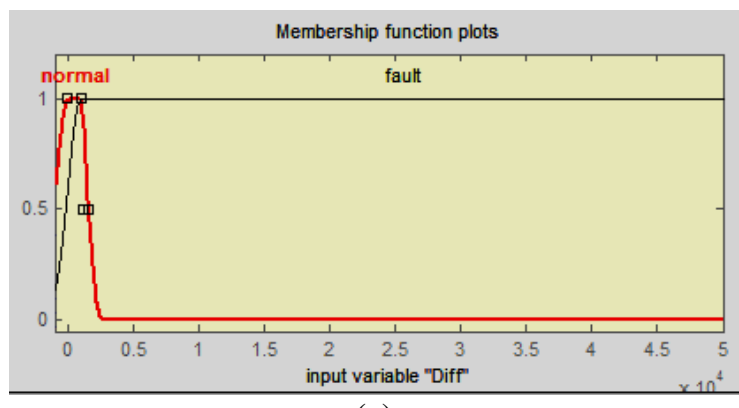

(a)

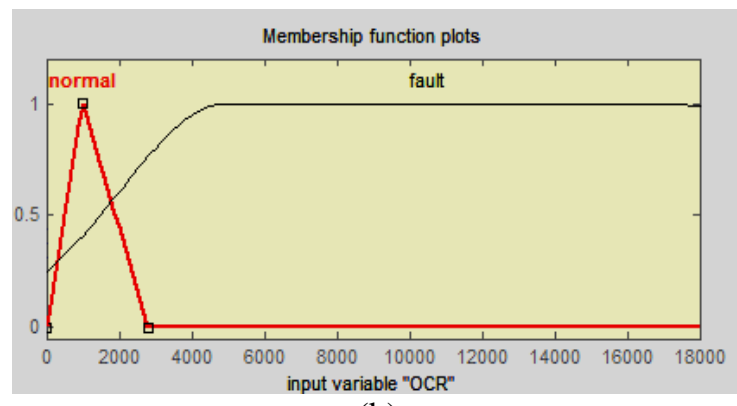

(b)

Figure 4. Input variables fuzzy membership function: (a) differential relay and (b) overcurrent relay

The range of first input membership is selected according to the range of difference in current presented in (3) during normal and abnormal operation. At the same time, the range of the membership for the second input is selected according to the maximum current value during regular operation. Figure 5 show the output variables membership function. The values of the two outputs represent the decision of trip or block according to the input values and the rules that organize the operation.

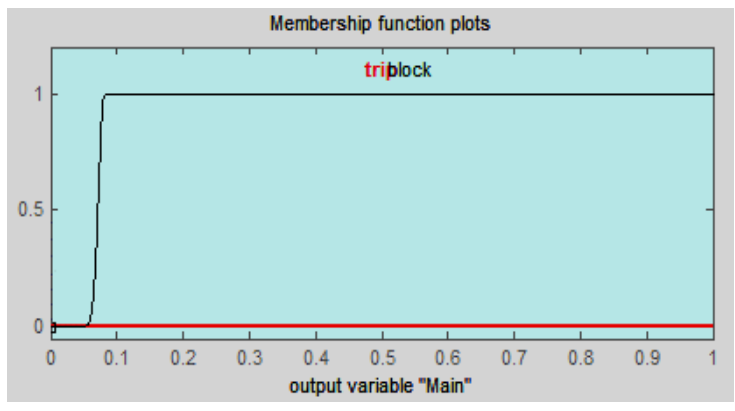

(a)

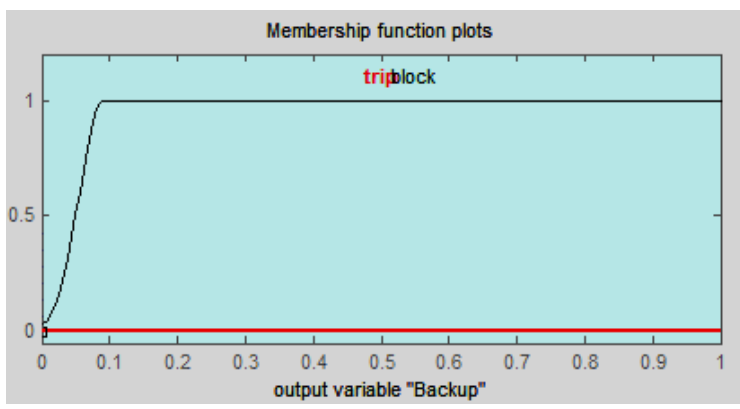

(b)

Figure 5. Output variable membership function: (a) main protection and (b) backup protection

\subsection{Proposed FLC rules}

For the proposed controller, four FLC rules selected to organize the operation of the overall protection system; these rules are listed in Table 1. From Table1, when input 1 and input 2 are normal, there is no fault on the system, so the circuit breakers of main and backup protection systems are still blocked. While

An improved technique for power transformer protection using fuzzy logic protective ... (Marwa M. Marei) 
if one of the two inputs becomes abnormal, it indicates a fault in the system. If input1 is abnormal (fault), output1 (main or unit protection) give a trip signal while if input 2 is abnormal (fault) while input 1 is normal (unit protection failure), output2 (backup protection) give a trip signal).

Table 1. Fuzzy logic protective rules

\begin{tabular}{lllll}
\hline & DifferentialRelay (Input1) & Overcurrent Relay (Input2) & Unit (Output1) & Backup (Output2) \\
\hline 1 & Normal & Normal & Block & Block \\
2 & Normal & Fault & Bock & Trip \\
3 & Fault & Normal & Trip & Block \\
4 & Fault & Fault & Trip & Trip \\
\hline
\end{tabular}

\section{CASE STUDY SIMULATION AND RESULTS}

The proposed model is simulated using MATLAB/SIMULINK package R2020b with a sampling time of 5*10-6 s and tested on actual data of a part of the Iraqi national grid, East Karbala substation $108 \mathrm{~km}$ southwest from Baghdad [26]. The overall simulation circuit diagram is shown in Figure 6. Mathworks simulation software is used to train and test the proposed solution under nominal power system operating conditions. Internal symmetrical faults on the high voltage side are among the fault types that were simulated. The East Karbala substation's technical features are shown in Table 2. The case study tested during regular operation and internal fault occurrence. The symmetrical three-phase fault is applied to one of the transformer terminals. The numerical results are shown in the figures.
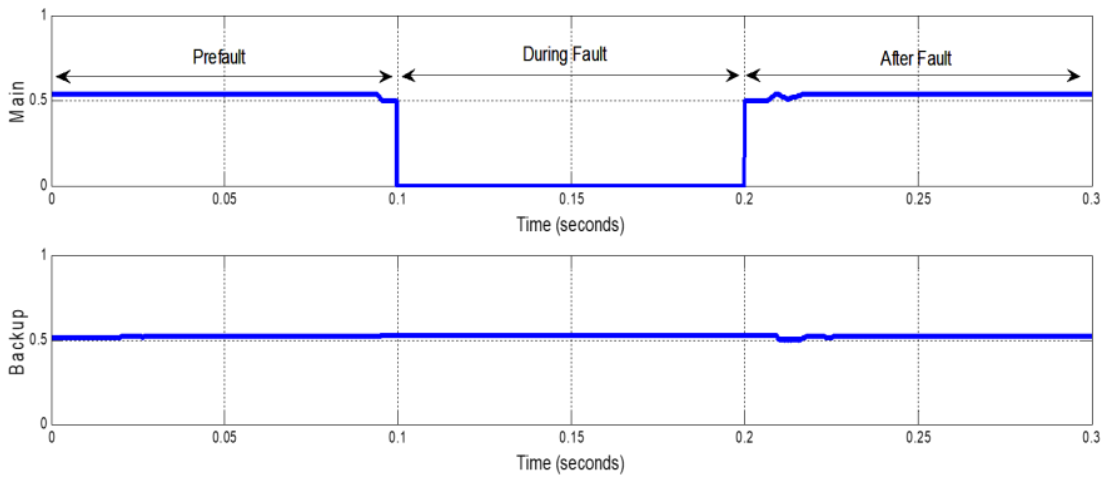

Figure 6. MATLAB simulation for East Karbala substation with its proposed protection system

Table 2. Technical features for east Karbala substation

\begin{tabular}{cll}
\hline \multicolumn{1}{c}{ Features } & \multicolumn{1}{c}{ Value } & \multicolumn{1}{c}{ Units } \\
\hline \multicolumn{1}{c}{$R_{1}$} & 0.01273 & $\Omega / \mathrm{km}$ \\
$L_{1}$ & $0.9337 \mathrm{e}-3$ & $\mathrm{H} / \mathrm{km}$ \\
$R_{0}$ & 0.3864 & $\Omega / \mathrm{km}$ \\
$L_{0}$ & $4.1264 \mathrm{e}-3$ & $\mathrm{H} / \mathrm{km}$ \\
Nominal power & 63 & $\mathrm{MVA}$ \\
Power correction & 0.85 & - \\
Operated voltage & 132 & $\mathrm{kV}$ \\
Length & 108 & $\mathrm{~km}$ \\
Power transformer & $\mathrm{D} 1 / \mathrm{Yg}$ & $63 \mathrm{kVA}$ \\
Rated frequency & 50 & $\mathrm{~Hz}$ \\
\hline
\end{tabular}

Figure 6 shows that during regular operation (pre-fault and after fault), the fuzzy logic protective relay gives a block signal to the circuit breakers, while during fault occurrence (during fault), the decision is to trip to isolate the fault from the system. During unit protection failure, the backup protection system is operated to isolate the fault, as shown in Figure 7. Figure 8 show the variation of power transformer voltage for different operating cases (pre-fault, during the fault, and after the fault) located before the position of the three-phase transformer. Figure 9 clarifies the waveforms of three-phase fault currents and voltage for different operating cases (pre-fault, during the fault, and after the fault) located before the position of the power transformer. 

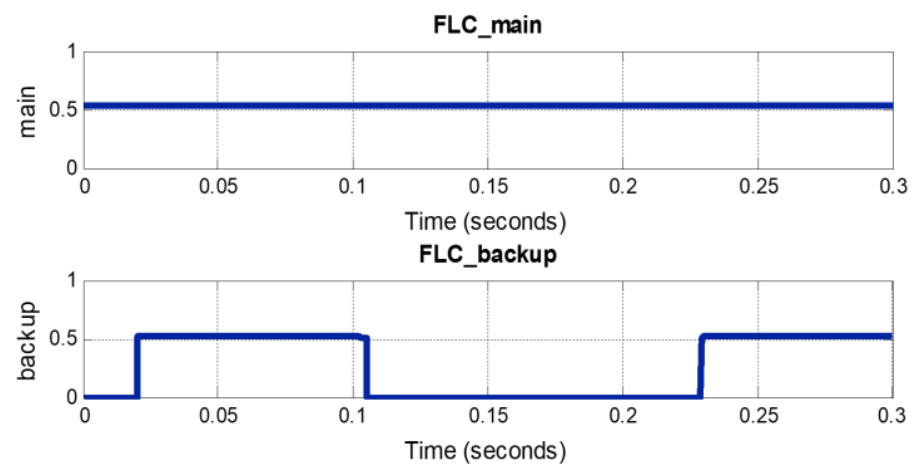

Figure 7. FLC decision during the unit protection failure
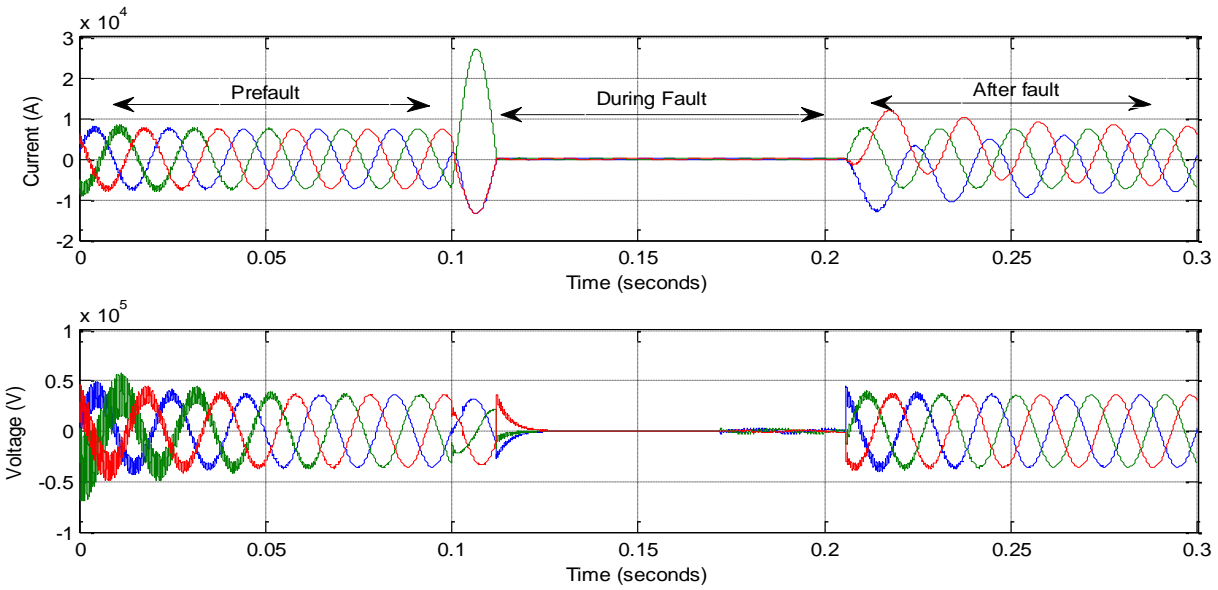

Figure 8. Transformer current and voltage pre-fault, during and after clearing fault
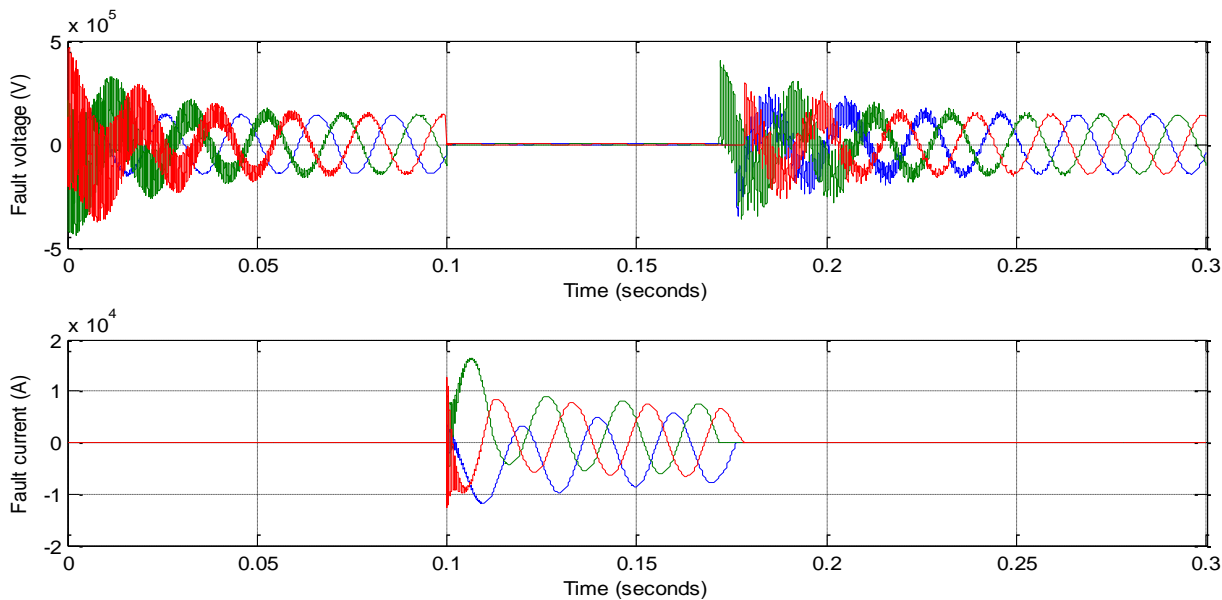

Figure 9. Waveforms of three-phase fault currents

\section{CONCLUSION}

This research focuses on reducing the difficulty of developing multi-systems to detect and manage the operation of power transformer primary and backup safety systems. The results show that fuzzy logic relaying is effective in modeling power system security due to its versatility and ease of adding logical conditions. It can be improved by changing the logical rules and physical variables instead of using two controllers used to detect the fault occurrence and make proper coordination between the relays' decision. The proposed protection uses one fuzzy logic protective relay to recognize the fault occurrence and coordinate the unit and backup protection systems' operation. Consequently, it gives an optimal decision to the circuit breakers connected to the export trip or 
block signal. In the next step of his study, the proposed scenario could be improved, modified, and applied to another type of protected equipment. The numerical results clarify that the proposed model can perform fast, accurate, and reliable protection for the power transformer.

\section{REFERENCES}

[1] A. A. Aziz, A. A. Ali and A. H. Abbas, "Power Transformer Protection by Using Fuzzy Logic," Iraq J. Electrical and Electronic Engineering, vol.5, no.1, pp. 1-11, 2009, doi: 10.33762/eeej.2009.54934.

[2] J. L. Blackburn, and J. D. Thomas, Protective relaying: principles and applications. Florida, USA: CRC Press, 2006.

[3] S. Miriyala and S. Ram, "Fuzzy Logic Techniques and Wavelet Transform Based Differential Protection for Power Transformer," International Journal of Innovative Research in Science, Engineering and Technology, vol. 5, no. 12, pp. 20775-20785, 2016, doi:10.15680/IJIRSET.2016.0512116.

[4] A. H. Ahmed, and A. J. Sultan, "Intelligent power transformer protection relay based fuzzy logic," International Journal of Engineering and Technology, vol. 7, no. 4, pp. 5882-5886, 2018, doi: 10.14419/ijet.v7i4.19632.

[5] A. S. Kumar, M. Saravanan, N. Joshna, and G. Seshadri, "Contingency analysis of fault and minimization of power system outage using fuzzy controller," International Journal of Innovative Technology and Exploring Engineering, vol. 9, no. 1, pp. 4111-4115, 2019, doi: 10.35940/ijitee.A4461.119119.

[6] C. R. Mason, The art and science of protective relaying. New York, USA: John Wiley \& Sons, 1967.

[7] Alstom (Firm), Network protection \& automation guide. Levallois-Perret, Paris, Prancis: Alstom, 2002.

[8] J. Faiz and S. Lotfi-Fard, "A novel wavelet-based algorithm for discrimination of internal faults from magnetizing inrush currents in power transformers," in IEEE Transactions on Power Delivery, vol. 21, no. 4, pp. 1989-1996, Oct. 2006, doi: 10.1109/TPWRD.2006.877095

[9] A. G. Phadke and J. S. Thorp, Computer relaying for power systems, New York, USA: John Wiley and Sons, 2009.

[10] M. V. Andreev, A. O. Sulaymanov and A. S. Gusev, "Simulation of differential protections of transformers in power systems," 13th International Conference on Development in Power System Protection 2016 (DPSP), 2016, pp. 1-6, doi: 10.1049/cp.2016.0094

[11] S. H. Horowitz, A. G. Phadke, and J. K. Niemira, Power system relaying. New York, USA: Wiley, 2014.

[12] Y. G. Paithankar and S. R. Bhide, Fundamentals of power system protection. Delhi, India: PHI Learning, 2011.

[13] R. Bouderbala, H. Bentarzi, and A. Ouadi, "Digital differential relay reliability enhancement of power transformer," International Journal of Circuits, Systems and Signal Processing, vol.5, no. 3, pp: 263-270, 2011.

[14] N. A. Al-Jawady, "Simulation of a three-phase differential relay for transformer protection," International Journal of Enhanced Research in Science Technology and Engineering, vol. 3, no. 2, pp. 174-182, 2014.

[15] S. Bagheri, Z. Moravej, and G. B. Gharehpetian, "Effect of transformer winding mechanical defects, internal and external electrical faults and inrush currents on the performance of differential protection," IET Generation, Transmission and Distribution, vol.11, no.10, pp: 2508-2520, 2017, doi: 10.1049/iet-gtd.2016.1239.

[16] M. Kezunovic and Yong Guo, "Modeling and simulation of the power transformer faults and related protective relay behavior," in IEEE Transactions on Power Delivery, vol. 15, no. 1, pp. 44-50, Jan. 2000, doi: 10.1109/61.847227.

[17] S. Al-Ameri, M. F. M. Yousof, N. Azis, S. Avinash, M. A. Talib, and A. A. Salem, "Frequency response of transformer winding to investigate the influence of RLC," Indonesian Journal of Electrical Engineering and Computer Science, vol. 14, no. 1, pp. 219-229, 2019, doi: 10.11591/ijeecs.v14.i1.pp219-229.

[18] M. Banerjee and A. Khosla, "Mitigation of magnetizing inrush current in three-phase power transformer," Indonesian Journal of Electrical Engineering and Computer Science, vol. 20, no. 1, pp. 39-45, 2020, doi: 10.11591/ijeecs.v20.i1.pp39-45.

[19] M. E. Yusoff and H. Hashim, "Analysis on the behavior of line differential protective relaying with solar PV penetration," Indonesian Journal of Electrical Engineering and Computer Science, vol. 20, no. 1, pp. 46-53, 2020, doi: 10.11591/ijeecs.v20.i1.pp46-53.

[20] M. S. Deshmukh and V. T. Barhate, "Microcontroller based differential relay using fuzzy logic for transformer protection," 2017 International Conference on Intelligent Computing and Control Systems (ICICCS), 2017, pp. 712-717, doi: 10.1109/ICCONS.2017.8250556.

[21] R. Arulmozhiyal and K. Baskaran, "Implementation of a fuzzy PI controller for speed control of induction motors using FPGA,” Journal of Power Electronics, vol. 10, no. 1, pp. 65-71, 2010, doi: 10.6113/JPE.2010.10.1.065.

[22] B. Kasztenny, E. Rosolowski, J. Izykowski, M. M. Saha and B. Hillstrom, "Fuzzy logic controller for on-load transformer tap changer," in IEEE Transactions on Power Delivery, vol. 13, no. 1, pp. 164-170, Jan. 1998, doi: 10.1109/61.660874.

[23] M. M. Marei and A. A. R. Altahir, "Digital protection for power transformer, a literature review," Technology Reports of Kansai University, vol. 62, no. 9, pp. 6365- 6369, 2020.

[24] V. R. Parihar, S. D. Nimkar, S. Warudkar, R. Deshmukh, and M. Thakare, "Power transformer protection using fuzzy logic based controller," International Journal of Engineering Research, vol.6, no.7, pp: 366-370, 2017, doi: 10.5958/2319-6890.2017.00039.3.

[25] A. M. Shah et al., "Quartile based differential protection of power transformer," in IEEE Transactions on Power Delivery, vol. 35, no. 5, pp. 2447-2458, Oct. 2020, doi: 10.1109/TPWRD.2020.2968725.

[26] M. M. Marei and M. H. Nawer, "Power losses reduction of power transmission network using the optimal location of lowlevel generation," International Journal of Electrical and Computer Engineering, vol. 10, no. 6, pp. 5586-5591, 2020, doi: 10.11591/ijece.v10i6.pp5586-5591. 